\title{
Key Performance Indicators (KPI) in Hospitality Industry: An Emphasis on Accommodation Business of 5 Star Hotels of National Capital Region
}

\author{
Prof. Nandini Srivastava* \\ Associate Professor- Management
}

\author{
Rekha Maitra
}

Assistant Professor -Hospitality

\begin{abstract}
A Performance Indicator or Key Performance Indicator (KPI) is a term used by industry or professionals for assessing or type of performance measurement.

KPIs are generally used by an organization in terms to evaluate their success and also the success of a particular effort which an individual or they are doing. Although success is sometimes defined in terms of making progress toward the expected goals or an event that accomplishes its intended purpose but often, success is simply the repeated achievement of some level of operational goal ...So for hospitality organisations and workers it becomes all the more important to set strategic goals, so choosing the correct KPIs is directly dependent on gaining an understanding of what is important to the organization.

Setting and achieving a clear understanding of EXPECTATIONS is a challenging task for front office managers and hospitality organisations. Identifying key responsibilities and then setting standards for evaluating employees on those expected set of factors has many trivial problems which are faced by both employees and employers.

'What is important' depends on the person measuring the performance - the indicators which are useful to one team will be different to the performance indicators of other team. There is a great need to develop a good understanding of what is important to an organisation, department or team and then developing an assessment tool. Use of these assessments then leads to the identification of potential improvements. This is the reason why performance indicators are generally associated with 'performance improvement' initiatives.

In hospitality organizations key performance indicators can be measured as per the role and responsibilities of each worker i.e. Hotel director, Hotel manager, Hotel assistant., Hotel supervisor, Hotel specialist, Hotel coordinator, Hotel clerk. The key responsibility area of these workers vary as per their departments i.e. Accommodation and food and beverage.
\end{abstract}

\section{Objective}

- To analyze the role of key performance indicators in hospitality industry with special emphasis on Accommodation Sector in Hospitality

- $\quad$ To identify the factors which affect the performance of accommodation industry i.e. Rev Par, Cost per occupied room, Average room rate etc.

\section{Methodology}

Research study is based on secondary data. Researcher has used various journals, research articles, newspapers, internet, books, e-books, reports published by various Research Agencies, etc. for this study.

\section{INTRODUCTION}

Concept of Key Performance indicators has become one of the most frequently used term in hospitality business development and management. It enacts as a guide to understand the key financial drivers in hospitality business i.e. Accommodation, food and beverage, profitability and liquidity. Hotel Industry is primarily made up of Accommodation, Food and Beverage division. Accommodation being the most costly product generates the maximum revenue for the hotel and if the accommodation product looses the opportunity of selling it, it loses the revenue forever.

In hospitality industry KPI should be providing employees with clear goals and objectives, coupled with an understanding of how they relate to the overall success of the organisation. Key Performance Indicators (KPI) is measurable factors that relate to an organisation's objectives i.e. Average room 
rate, Bed occupancy percentage rate, cost per occupied room, revenue available per room and labour cost ratio.

Key performance indicators of hospitality industry are as follows:

\begin{tabular}{|l|l|l|}
\hline Accommodation & Food & Beverage \\
\hline Average Room Rate & Cost of Sales Ratio; & Cost of Sales Ratio \\
\hline Bedroom Occupancy Rate & Gross Profit Ratio & Gross Profit Ratio \\
\hline Revenue per Available Room & Average Spend per customer & Average Spend per customer \\
\hline Cost per Occupied Room & Labour Cost Ratio. & Labour Cost Ratio. \\
\hline Labour Cost Ratio & & \\
\hline
\end{tabular}

Source: (Failte, 2013)

Hotel industry utilizes indexes to measure performance in three key areas: Occupancy, Average daily rate (ADR) and Revenue per available room (Rev PAR). An index of 100 means a hotel is capturing a fair share compared to the aggregated group of hotels.

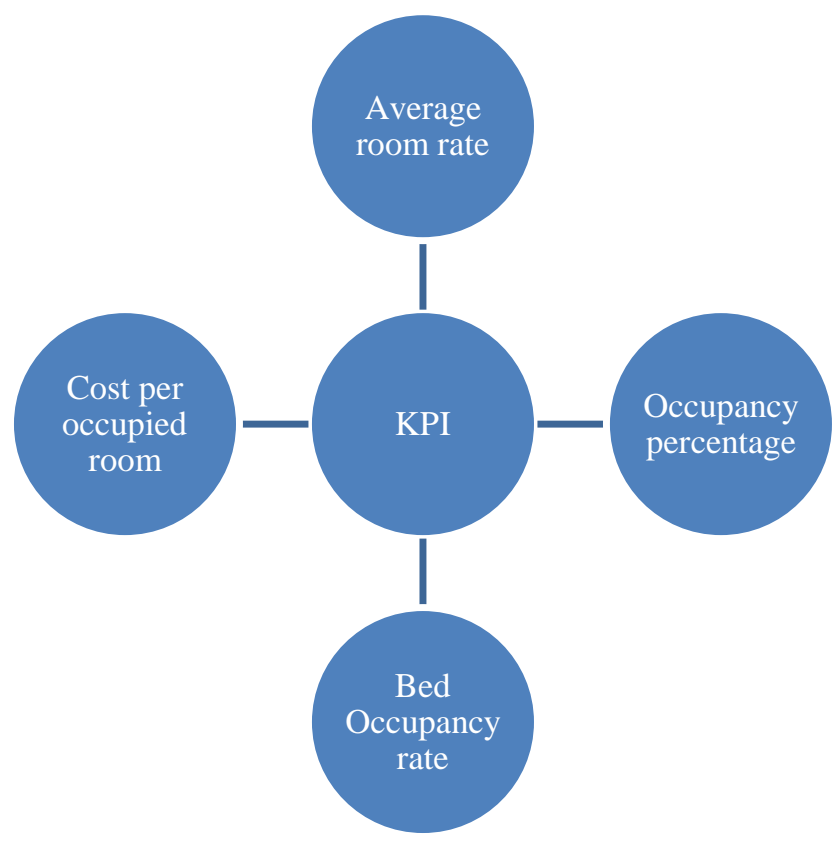

Brief introduction of KPI Indicators are as follows:

- Average Room Rate: It refers to the average room revenue per occupied room in a hotel for a specific period. It is also known as Average daily rate. Managers rely on this ratio in determining whether, or not, the premises are being utilized efficiently and whether expansion is possible.

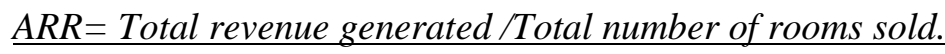

- Bedroom Occupancy Rate is calculated by dividing the number of rooms sold by the number of rooms available, as follows:

Bedroom occupancy rate $=\%$ number of rooms sold/number of rooms available $\times 100$

- Occupancy Percentage Rate: Refers to the ratio of total number of occupied rooms to the total number of rooms available for sale.

- Cost per Occupied Room /Average Room Rate per Guest (ARG): Calculation for this is developed by dividing the total room revenue by the total number of guests in the hotel. The formula is as follows:

\section{Cost per occupied room $=\epsilon$ total rooms department cost/ number of rooms sold}

- Revenue available per room: It is a performance measure used in hotel industry computed by dividing a hotel's total guestroom revenue by the room count and the number of days in the period being measured.

$\underline{\text { Rev Par }=\text { Rooms revenue/Revenue available }}$ 
KPIs help hospitality organisations to understand how well they are performing in relation to their strategic goals and objectives.

A KPI provides the performance information that enables organisations or their stakeholders to understand whether the organisation is on track or not. In organisation to improve performance it is very important to have clear performance indicators along with commitment. Developing performance indicators in organisation is a difficult task not only for the organisation but also the government departments as well. The development of appropriate machinery which can link performance to the performance indicators for employees is a challenge in itself.

Performance Indicators: The definition of a performance indicator from an NCOSS publication is: A numerical measure of the degree to which the objective is being achieved. Performance indicators are quantitative measures and control points of individual performance. To develop Key performance indicators it is essential to keep the following points under consideration:

- Complete understanding of organisation's values, mission and vision

- Understanding the nature of business and its customers

- Knowledge of standard operating procedures and what has to be achieved at each step

KPIs are required to be linked to the strategy of the organisation and after mapping your strategy KPIs can be listed to track progress to manage and improve performance. KPIs should be primarily designed to empower employees by providing them with the relevant information to learn. This helps to improve the decision making and results in improved performance. The process of designing KPI's start with outlining the Key performance questions for each strategic objective. KPI's are the reflection of individual performance in a simpler and evaluative form. While designing and assessing the performance the following steps need to be kept in mind:

- Identify the factors critical to performance.

- Collect and report the required data

- Analyse the data for the use of improving and measuring performance

\section{LITERATURE REVIEW}

The Indian Hotel Industry Survey 2013-2014 reflects a positive change indicated by the key operating Statistics, which may be an early indicator towards the end of a downturn for the Indian hotel industry (President, 2014)

Global hospitality and leisure transactions increased 8\% year-over-year through Q3 2014, showing that the industry continues to gain momentum even in the face of accelerating geopolitical instability, health and terrorism concerns. (Lang)

A wave of new hotels will open in 2015, and a robust global development pipeline of approximately 1.3 million guestrooms is in place. (New Hotel Construction Pipeline in Global Shift,")

The tourism and hospitality sector is among the top 15 sectors in India to attract the highest foreign direct investment (FDI). During the period April 2000-February 2015, this sector attracted around US\$ 7,862.08 million of FDI, according to the data released by Department of Industrial Policy and Promotion (DIPP).

As per ICRA Research, "India has over 29,000 premium rooms under construction- to be launched over the next six years. As a result of supply-demand mismatch", ICRA suggest, Industry players have been resorting to significant belt tightening by keeping a check on key cost drivers like payroll expenses, which have gone up only by an estimated 4 per cent over the last three fiscals (Times, 2015)

"Key Performance Indicators (KPIs) or ratios are based on the key drivers of your Business and they reflect the performance and the progress of your business. It is good practice within the hotel industry especially, and the hospitality and tourism industry generally, to use a series of standard Key Performance Indicators to monitor and to benchmark performance" (Failte, 2013)

India has the 2nd largest population in the world. India has great long term potential as an outbound tourism market. The country's tourism is the 3 rd largest foreign exchange earner, Accounting for 
almost $2.5 \%$ of the GDP. The WTO predicts the India will account for 50 million outbound tourists by 2020. (naik, 2012)

It is very evident from the literature review that hospitality industry in India is growing rapidly. Present study is an attempt to take an overview of accommodation sectors of Hospitality Industry in Delhi and NCR .This study is also an attempt to present some suggestions to hoteliers to maximise their performance in Delhi and NCR

\section{DISCUSSION}

The objectives of the organization are required to be measurable i.e. increasing the average room revenue by 15 percent in comparison to previous year performance, increasing the foreign occupancy percentage by 20 percent etc.

In this research study following parameters of key performance indicators have been discussed for deriving results

1. Occupancy and Average room rate of hotels from year 2009-2014

2. Sources of revenue from year 2009-2014.

3. Occupancy percentage trend on weekdays and weekend in New Delhi

4. Average daily rate trend on weekdays and weekend in New Delhi

5. Movement in ARR of 5 star deluxe, 5 star and 4 star

i. Occupancy and Average Room Rate of Hotels in India from Year 2009-2014

EXHIBIT 1: Occupancy and Average Rate (2009-10 to 2013-14)

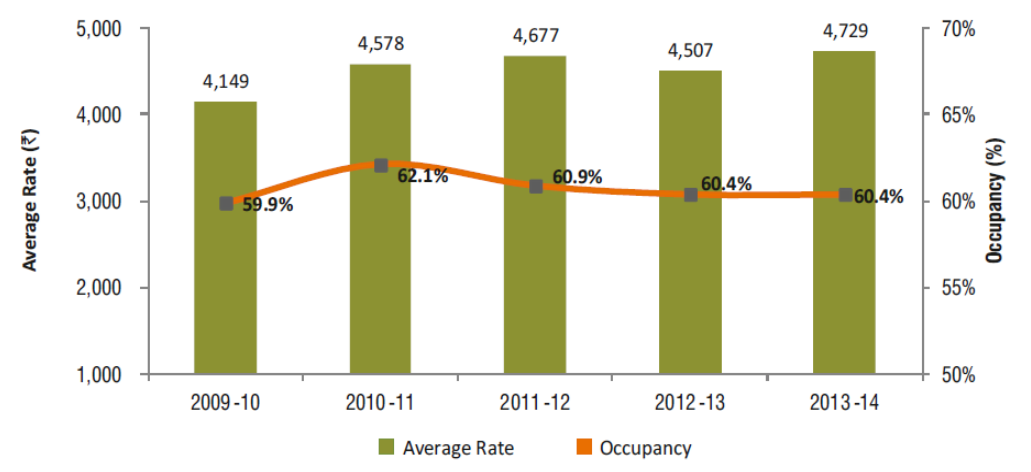

Source: HVS 2014 Hotels In India Trends And Opportunities Report

As per the given report of HVS 2014 Occupancy percentage in 5 star hotels remained at $60 \%$.The average room rate (ARR) was the highest in $\mathbf{2 0 1 3 - 1 4}$ in last 5 years, increasingly by $4.9 \%$ to close at Rs.4, 729.

\section{ii. Sources of Revenue from Year 2009-2014}

EXHIBIT 2: $\underline{\text { Sources of Revenue (2009-10 to 2013-14) }}$

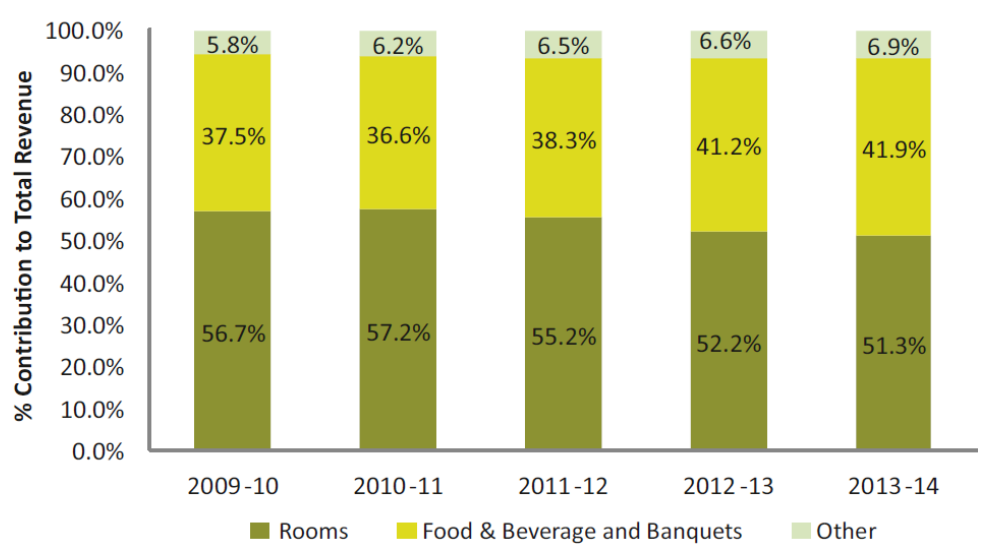

Source: HVS 2014 Hotels in India Trends and opportunities Report 
As per the given exhibit there has been a continued change in the sources of revenue composition over the past few years. Although ARRs saw a marginal increase, the trend of declining revenues from the Rooms division continued in 2013-14, falling from 52.2\% in 2012-13 to 51.3\% in 2013-14. The contribution of Food and Beverage $(\mathrm{F} \& \mathrm{~B})$ revenue, On the other hand, it has increased marginally from 41.2\% in 2012-13 to 41.9\% in 2013-14 with rising contribution from Banquets and Conferences. Additionally, other revenue that includes laundry, gift shop, business centre, health club and rentals also saw a slight growth from $6.6 \%$ in $2012-13$ to $6.9 \%$ in 2013-14.

\section{iii. Occupancy Percentage Trend on Weekdays and Weekend in New Delhi}

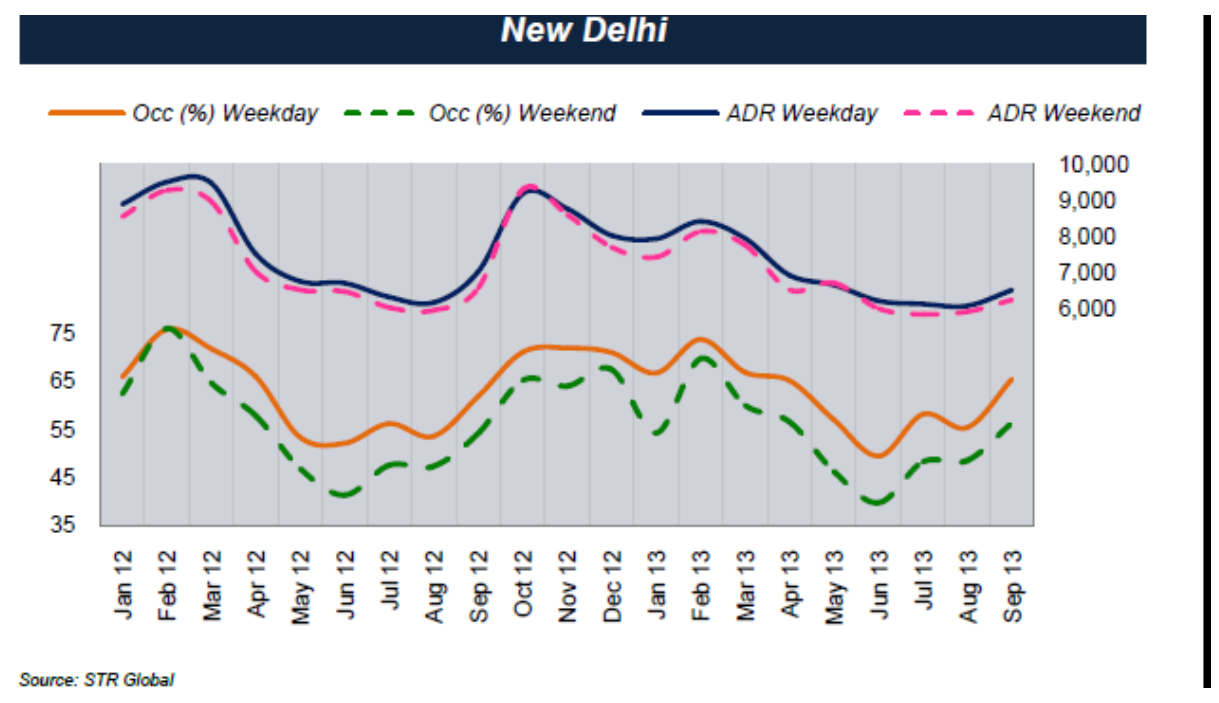

(Source: STR Global)

As per the given data of New Delhi hotels, it is evident from a point of near equality in Jan and Feb 12 , there has been a steady variation between weekday and weekend occupancies - importantly, the degree of variation in occupancy and Rev PAR has been the narrowest for New Delhi compared to other markets.

- Average weekday and weekend occupancy have declined by 2.2 pts and 4.6 pts respectively between 2012 and YTD 2013; what needs to be watched is whether the gap will continue to widen due to lack of conference facilities in Delhi based hotels; the development of newer hotels and lack of corporate growth in Delhi city are factors that could significantly impact Delhi hotels going forward.

\section{iv. Average Daily Rate Trend on Weekdays and Weekend in New Delhi}

The NCR consists of hotels located in Delhi, Faridabad, Ghaziabad, NOIDA, and Greater NOIDA. As the capital and the leading growth centre of the country, despite supply pressures, Delhi continues to be a strong market for hotels. Delhi has witnessed the commissioning of the first hospitality district in the country (Delhi Aero city), where four hotels started operations in 2013-14. Although the city saw the introduction of these hotels, Delhi witnessed a moderate increase in occupancy in 2013-14 as compared to that in 2012-13. Brisk uptake of transient visitors and MICE demand by the aero city hotels highlights the quantum of latent demand in these market segments. Going forth, with a stable government in place, hospitality industry expects the more traditional generators of business (government bodies, diplomatic missions and public sector companies) to pick up pace. On the supply front, Hospitality Industry anticipates the addition of over 3,700 rooms predominantly in the aero city area over the next few years. While this may result in pressure on both occupancy and average rate, these would be short lived and remain positive about the market in the medium to long term.

NOIDA and Greater NOIDA have gradually developed over the past ten years into centres of industrial activity. Historically, the two towns have contained a very small base of hotels, which in addition to catering to demand emanating from the two cities, accommodated some demand from the neighbouring pockets of Ghaziabad and East Delhi. Continuous improvements in infrastructure and the construction of new residential projects have made NOIDA and Greater NOIDA attractive for investment. Consequently, hotel supply grew from 300 branded rooms in 2009-10 to 11,100 rooms in 
2013-14. Hotel supply has increased in East Delhi and Ghaziabad areas as well. Supply pressure along with slow growth in demand has caused severe rate pressures in this micro market. With sluggish increase in demand combined with a steady growth in supply (1,700 rooms over the next five years), the micro market will continue to face occupancy and rate pressures.

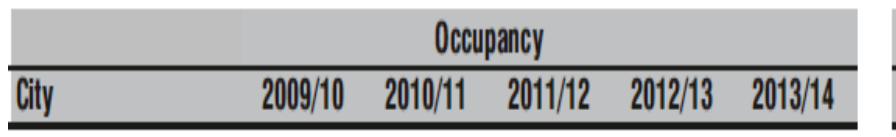

\begin{tabular}{lrrrrr}
\hline All India & $59.9 \%$ & $62.1 \%$ & $60.9 \%$ & $60.4 \%$ & $60.4 \%$ \\
\hline Agra & $57.0 \%$ & $63.2 \%$ & $68.3 \%$ & $60.3 \%$ & $57.7 \%$ \\
\hline Ahmedabad & $65.7 \%$ & $67.6 \%$ & $65.1 \%$ & $63.0 \%$ & $60.4 \%$ \\
\hline Aurangabad & $57.9 \%$ & $59.5 \%$ & $\mathbb{I D}$ & $49.0 \%$ & $\mathbb{I D}$ \\
\hline Bengaluru & $52.6 \%$ & $53.8 \%$ & $58.7 \%$ & $56.6 \%$ & $59.7 \%$ \\
\hline Bhopal & $66.1 \%$ & $\mathbb{I D}$ & $78.0 \%$ & $72.4 \%$ & $67.7 \%$ \\
\hline Chandigarh & $69.1 \%$ & $70.4 \%$ & $\mathbb{I D}$ & $65.4 \%$ & $54.9 \%$ \\
\hline Chennai & $65.6 \%$ & $64.8 \%$ & $69.1 \%$ & $69.8 \%$ & $68.2 \%$ \\
\hline Coimbatore & $75.5 \%$ & $72.8 \%$ & $66.5 \%$ & $61.3 \%$ & $59.3 \%$ \\
\hline Delhi-NCR* & $64.6 \%$ & $59.0 \%$ & $61.4 \%$ & $57.1 \%$ & $57.7 \%$
\end{tabular}

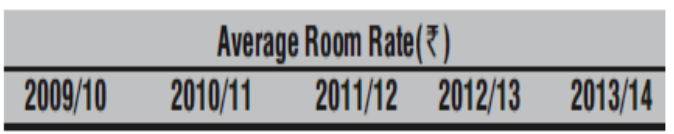

\begin{tabular}{rrrrr}
\hline 4,149 & 4,578 & 4,677 & 4,507 & 4,729 \\
\hline 2,482 & 3,968 & 3,974 & 4,381 & 3,988 \\
\hline 3,367 & 3,234 & 3,650 & 3,902 & 3,106 \\
\hline 2,850 & 2,612 & $\mathbb{I D}$ & 3,203 & $\mathbb{I D}$ \\
\hline 6,766 & 5,838 & 6,849 & 5,533 & 6,300 \\
\hline 3,110 & $\mathbb{D}$ & 3,827 & 4,300 & 3,366 \\
\hline 4,780 & 4,544 & $\mathbb{I D}$ & 3,639 & 4,396 \\
\hline 4,083 & 5,508 & 4,365 & 4,345 & 4,043 \\
\hline 3,236 & 3,989 & 4,100 & 3,655 & 2,987 \\
\hline 6,985 & 6,763 & 7,319 & 7,455 & 8,282 \\
\hline
\end{tabular}

Source: HVS and FHRAI Indian Hotel Survey on Delhi-National Capital Region

As per the given exhibit of HVS and FHRAI Indian Hotel Survey the occupancy percentage and average room rate has kept changing over the last 5 years. In All India hotels Occupancy percentage remained at $59.9 \%$ in $2009-10,62.1 \%$ in $2010-11,60.9 \%$ in $2011-12,60.4 \%$ in $2012-13$ and $2013-$ 14.Slight changes are being observed in Average room rate of all India Hotels .In 2009-10 ARR remained at Rs.4, 149, Rs.4, 478 in 2010-11, Rs. 4,677in 2011-12, Rs.4, 507 in 2011-12 and Rs. 4,729 in 2013-14.

Indian hotel survey depicts an exhibit of Delhi and National Capital region of 5 star hotels

$>$ Occupancy percentage of Delhi-NCR (excluding Gurgaon) the occupancy percentage was $64.6 \%$, $59 \%$ in $2010-11,61.4 \%$ in $2011-12,57.1 \%$ in $2012-13$ and $57.7 \%$ in $2013-14$.

$>$ Increasing average room rate is being noticed over the years ARR was at Rs. 6,995/ in 2009-10, Rs. 6,763 in 2010-11, Rs. 7319 in 2011-12, Rs. 7,455 in 2012-13 and Rs. 8,282 in year 2013-14

\section{v. Movement in ARR of 5 Stars Deluxe, 5 Star and 4 Star Hotels}

Movement in ARR depicts the performance of Front Office department in hospitality organization. Higher ARR represents profit wherein lower ARR represents marginal profit. Therefore, it becomes evident for hospitality organizations to maintain the higher average daily rate.

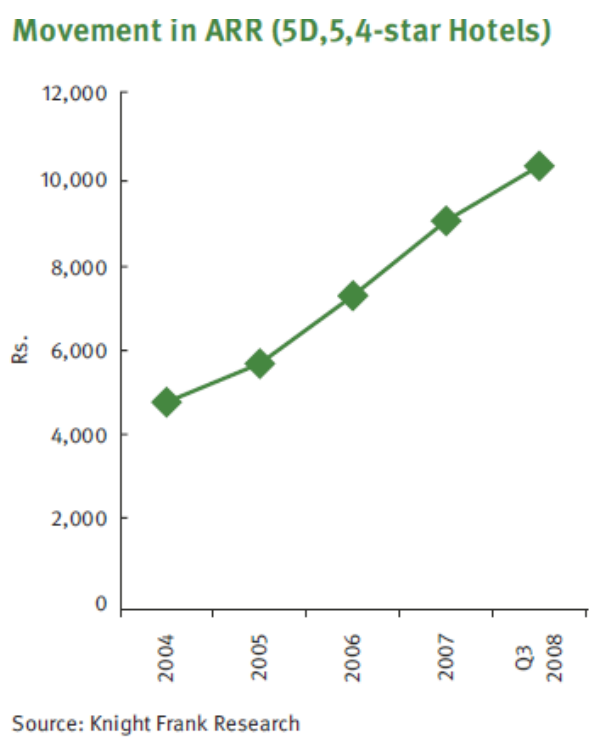


Key Performance Indicators (KPI) in Hospitality Industry: An Emphasis on Accommodation Business of 5 Star Hotels of National Capital Region

The above chart depicts movement in ARR of ( 5 star deluxe, 5 star and 4 star hotels . There has been steady growth in time span of 4 years from 2004 to 2008.ARR OF Rs.4, 500 has seen a growth up to Rs.5, 800, 7, 500, 8500 and finally it has risen up to Rs.10, 000 in year 2008.

\section{CONCLUSION}

The above mentioned review enables us to conclude the following:

- When an organisation or business decides over the factor which needs to be improved, KPIs i.e. Revenue are required to differentiate amongst the other business areas involved.

- An organisation wide approach toward the mission statement of companies has positive effect, producing synergistic effect, and cultivates team spirit.

- For providing the right blend of services and luxury with efficiency can be met by having a strategic goal, which will further require highly motivated and well-trained staff to provide attentive, personalized and warm service.

- KPIs can be formed only with an in depth understanding of what is possible. The organisation should constitute KPI in reference to market forces and how the competition is performing. This means that an understanding of standards is essential to make KPI's useful and useful to the organisation. With KPIs in place it becomes easy for organisation to assess performance of hotels.

The Company must set few goals and strategies to meet objectives of Key performance indicators. The aim should be to equip employees with the information they need to make better informed decisions that lead to Improvements. The organisations need to understand that it is difficult to design perfect indicators that will measure things perfectly. KPIs are there to give information which helps us to take better decisions

\section{BIBLIOGRAPHY}

[1] Failte. (2013, October 29). Key Performance Indicators. Ireland

[2] Lang, J. (n.d.). Global Market Perspective Q4 2014: Hotel investment. Retrieved 2015 September, from www.jll.com/gmp/market-perspective/hotels,.naik, S. S. (2012). India:Key be merging market for hospitality industry. International Journal of Trade and Commerce, Volume 1, No. 2, pp. 2 New Hotel Construction Pipeline in Global Shift," (n.d.). Retrieved from www.hotelinteractive.com/article

[3] President, F. (2014). Indian Hotel Industry Survey. New Delhi: FHRAI and HVS

[4] Times, T. E. (2015, jan 24). Indian hotel industry's revenues to raise 7-9 per cent in FY15: ICRA. Retrieved August 25, 2015, from http://articles.economictimes.indiatimes.com/2015-0127/news/58508218_1_indian-hotel-industry-next-12-18-months-cent

[5] KOTZE Stuart Robin (2008), Performance: The Secret of Successful Behavior, Pearson Education Ltd.

[6] Whiteman C. Martha, Deary J.Ian, Mathews Gerald (2003), Personality Traits (Second Edition), U.S.A., Cambridge University Press.

[7] Parmenter David, Key Performance Indicators: Developing, Implementing \& using winning KPI's (Second Edition), U.S.A, John Wiley \& Sons Inc.

[8] Krauth Elfriede, Moonen Hans,Popova Viara and Schut Martijn, (2005) The IUP Journal of Management Research.

[9] Batra Roopali (2006) the IUP Journal of Management Research.

[10] www.managementhelp.org 